\title{
Asymptomatic carotid artery stenosis: time to rethink our therapeutic options?
}

\author{
Saul F. Morales-Valero, M.D., and Giuseppe Lanzino, M.D. \\ Department of Neurologic Surgery, Mayo Clinic, Mayo Medical School, Rochester, Minnesota
}

\begin{abstract}
Asymptomatic carotid artery stenosis is a well-recognized risk factor for ischemic stroke, and its prevalence increases with age. In the late 1980s and in the 1990s, well-designed randomized trials established a definite advantage for carotid endarterectomy in reducing the risk of ipsilateral stroke when compared with medical therapy alone. However, medical treatment of cardiovascular disease has improved significantly over the past 2 decades, and this has, in turn, resulted in a decline of the stroke risk in patients with asymptomatic carotid artery stenosis treated medically. This improvement in medical therapy casts doubts on the effectiveness of large-scale invasive treatment in patients with asymptomatic carotid artery stenosis. Several studies have been conducted to identify possible subgroups of patients with asymptomatic stenosis who are at higher risk of stroke in order to maximize the potential benefits of invasive treatment. Ongoing large-scale trials comparing best current medical therapy to available invasive treatments, such as carotid endarterectomy and carotid artery stenting, are likely to shed some light on this debated topic in the near future. In this review, the authors summarize the current controversy surrounding the ideal management of asymptomatic carotid artery stenosis.
\end{abstract}

(http://thejns.org/doi/abs/10.3171/2013.10.FOCUS13389)

KEY WoRdS - carotid artery stenosis • stroke • carotid endarterectomy

$\mathrm{T}$ He prevalence of asymptomatic carotid artery stenosis varies according to age and sex. In a recent systematic review of population-based studies, moderate stenosis $(\geq 50 \%)$ was found in $4.8 \%$ of men and $2.2 \%$ of women younger than 70 years. The percentages increase to $12.5 \%$ in men and $6.9 \%$ in women if patients older than 70 years are considered. ${ }^{8}$ Data regarding severe asymptomatic stenosis $(\geq 70 \%)$ indicate that its prevalence ranges from $0 \%$ to $3.1 \%$ of the general population. ${ }^{9}$ Given the increase in prevalence with age and the aging population, asymptomatic carotid artery stenosis can be expected to be very common in modern medical practices.

About one-third of all strokes are related to large artery thromboembolism, ${ }^{4,12}$ and it is well recognized that carotid artery stenosis is a risk factor for ischemic stroke. ${ }^{26,34}$ Large randomized, multicenter studies have been conducted to assess the role and efficacy of carotid endarterectomy (CEA) and, more recently, carotid artery stenting (CAS) in patients with asymptomatic carotid artery stenosis. These seminal trials have demonstrated a

Abbreviations used in this paper: ACAS = Asymptomatic Carotid Atherosclerosis Study; ACSRS = Asymptomatic Carotid Stenosis and Risk of Stroke; ACST = Asymptomatic Carotid Surgery Trial; CAS = carotid artery stenting; CEA = carotid endarterectomy; CREST $=$ Carotid Revascularization Endarterectomy vs Stenting Trial; $\mathrm{TCD}=$ transcranial Doppler; TIA $=$ transient ischemic attack. marginal but definite benefit for CEA in reducing the risk of stroke after 5 and 10 years when compared with "best" medical therapy alone. However, these studies were conducted in the late 1980s and in the 1990s, and since their completion, progress in the medical management of cardiovascular diseases has led to a progressive decrease in the yearly risk of stroke in patients with asymptomatic carotid artery stenosis managed with medical treatment alone. Thus, some have questioned the effectiveness of large-scale invasive treatment (CEA or CAS) in view of the significant improvement of medical therapy. In this review, we summarize the available data and the ongoing controversy related to this issue.

\section{Evidence Supporting Surgical Intervention for Asymptomatic Carotid Artery Stenosis}

Two main studies have shaped the surgical treatment of asymptomatic carotid artery stenosis in the past 20 years: the Asymptomatic Carotid Atherosclerosis Study (ACAS) in North America and the Asymptomatic Carotid Surgery Trial (ACST), conducted mostly in Europe. In ACAS, the main objective was to assess whether CEA (in addition to medical therapy) reduced the 5-year risk of ipsilateral stroke in individuals with hemodynamically significant asymptomatic carotid artery stenosis (defined as $\geq 60 \%$ reduction in lumen diameter) when compared with medical therapy alone. "Best medical therapy" at the 


\section{S. F. Morales-Valero and G. Lanzino}

time of this trial was fairly simple and consisted mostly of daily aspirin combined with "reduction" of modifiable risk factors. A total of 1662 patients were randomized from different medical centers across the United States and Canada. The study was stopped early, after a median follow-up of 2.7 years, due to a significant difference favoring CEA. The estimated 5-year risk of ipsilateral stroke was reduced from $11 \%$ in individuals treated with medical therapy alone to $5.1 \%$ in those undergoing CEA, for an absolute risk reduction of $5.9 \%$ (or $1.2 \%$ per year). ${ }^{43}$

The ACST was initiated in 1993 and enrolled a much larger number of patients than ACAS. The primary objective of ACST was to assess the long-term effects of CEA on any stroke in patients with significant (defined as $>60 \%$ lumen reduction on Doppler ultrasonography) asymptomatic carotid artery stenosis. It is important to mention that, in ACST, asymptomatic patients were considered those without any relevant neurological symptoms during the 6 months preceding enrollment. A total of 3120 patients were randomized to undergo immediate CEA while receiving intensive medical management or medical management alone; the mean follow-up period was 3.4 years. An absolute risk reduction of $5.4 \%$ was seen in the rate of any stroke and perioperative events when comparing immediate versus deferred surgery $(6.4 \%$ vs $11.8 \%)$. There was also a significant difference in the risk of carotid territory stroke and fatal or disabling stroke between both groups. The overall perioperative stroke and death rate in this study was 3.1\%. ${ }^{16}$

The 10-year data from ACST were published in $2010 .{ }^{15}$ The 10-year risk of any stroke and perioperative events was $13.4 \%$ in the CEA group and $17.9 \%$ in the medical arm, representing an absolute risk reduction of $4.6 \%$. During this period, substantial improvement in medical therapy was noted among individuals enrolled, especially in regard to the increased use of lipid lowering agents. The benefit of immediate CEA was not present across all age groups, being significant for men and women up to 75 years of age at the time of enrollment. Surgical intervention did not benefit patients older than 75 at the time of enrollment due to their increased probability $(>50 \%)$ of dying from a variety of causes rather than stroke during the 10 -year follow-up period. ${ }^{15}$

It is often said that ACAS and ACST reported a similar overall stroke risk reduction favoring CEA, but this is not true. A fundamental difference between the two studies is the primary end-point: ipsilateral stroke in ACAS and any territory stroke in ACST. As we will elaborate later, careful analysis of the two studies actually does confirm a progressive decrease in the risk of ipsilateral stroke in parallel with improvements of medical therapy. ${ }^{30}$ Table 1 shows a comparison between the ACAS and ACST trials.

In the past 2 decades, CAS has been proposed as an alternative to CEA. While CEA and CAS have been extensively studied in symptomatic patients in several randomized trials, only very few studies have compared the two therapeutic modalities in patients with asymptomatic stenosis. Thus, data supporting CAS for asymptomatic carotid artery stenosis are very limited at present. ${ }^{36}$ The best data available for CAS in asymptomatic patients come from the Carotid Revascularization Endarterectomy vs Stenting Trial (CREST). ${ }^{6,36}$ During this study, both symptomatic and asymptomatic patients were randomized to undergo either CEA or CAS, and after a median follow-up period of 2.5 years the initial results were reported. Among the asymptomatic patients, the estimated 4-year risk of stroke or death (including perioperative events) was $2.7 \%$ with CEA and $4.5 \%$ with CAS. However, this difference was not found to be statistically significant $(\mathrm{p}=0.07)$ because the study was not powered to perform subgroup analysis. (Among the 2502 patients studied, there were 1181 asymptomatic patients; 594 in the CAS group and 587 in the CEA group, with a small number of endpoint events.)

\section{Evidence Supporting Medical Therapy Alone}

In the past 2 decades, important advances in medical therapy for cardiovascular diseases have taken place. Antiplatelet, antihypertensive, and lipid-lowering agents are commonly used in patients at risk for atherosclerosis, and great emphasis is placed on the importance of exercise, weight loss, and smoking cessation. All of these interventions, aimed at achieving specific clinical or biochemical targets, have ultimately led to a reduction in the rate of cardiovascular events, including stroke. ${ }^{20}$ Improvement in medical therapy and cardiovascular risk-factor modification are the main reasons why many clinicians argue against the widespread use of CEA and CAS for asymptomatic patients. ${ }^{25,31,38}$

A number of studies and observations have indeed confirmed a progressive reduction in the yearly risk of stroke in patients with asymptomatic carotid artery stenosis since completion of the above-mentioned CEA trials. These studies have methodological limitations, as many variables such as weight loss, smoking, and physical activity were not adequately controlled. However, they provide convincing data to support a decreased rate of stroke with modern medical therapy in patients with asymptomatic carotid artery stenosis.

A prospective, cohort study of 101 patients was conducted from 2002 to 2009 to determine the risk of ipsilateral stroke in patients with at least $50 \%$ asymptomatic carotid artery artery stenosis on intensive medical treatment. In this study, intensive therapy consisted of antiplatelet, lipid-lowering, and antihypertensive medications in more than $80 \%$ of patients, as well as appropriate glucose control measures and lifestyle modifications. After a mean follow-up of 3 years, 6 ischemic events occurred in the territory of the asymptomatic carotid artery stenosis, and 5 of these events were transient ischemic attacks (TIAs), with only 1 patient suffering a nondisabling stroke. Average annual risks were $0.34 \%, 0 \%$, and $1.78 \%$ for any ipsilateral stroke, disabling ipsilateral stroke, and ipsilateral TIA, respectively. ${ }^{28}$ These annual rates are much lower than those reported in the large clinical trials favoring CEA.

The benefits of medical therapy were convincingly demonstrated by another prospective study of patients with asymptomatic carotid artery stenosis conducted between 2000 and 2007. Two periods were compared: be- 
Management of asymptomatic carotid artery stenosis

TABLE 1: Comparison between design and outcomes of ACAS and ACST*

\begin{tabular}{|c|c|c|c|}
\hline \multirow[b]{2}{*}{ Variable } & \multicolumn{2}{|c|}{ 5-Year Outcomes } & \multirow{2}{*}{$\begin{array}{c}\text { 10-Year Outcomes } \\
\text { ACST }\end{array}$} \\
\hline & ACAS & ACST & \\
\hline period of recruitment & $1987-1993$ & \multicolumn{2}{|c|}{$1993-2003$} \\
\hline no. of patients enrolled & 1662 & \multicolumn{2}{|c|}{3120} \\
\hline symptomatic status & never symptomatic & \multicolumn{2}{|c|}{ asymptomatic 6 mos or longer } \\
\hline endpoint & $\begin{array}{l}\text { ipsilateral stroke or any perioperative } \\
\text { stroke/death }\end{array}$ & \multicolumn{2}{|c|}{$\begin{array}{l}\text { any non-perioperative stroke \& perioperative mortality/ } \\
\text { morbidity }\end{array}$} \\
\hline follow-up (yrs) & 2.7 & 3.4 & 9 \\
\hline perioperative risk (\%) & 2.3 & 3.1 & 3.0 \\
\hline \multicolumn{4}{|l|}{ risk of stroke $(\%)$} \\
\hline CEA & 5.1 & 6.4 & 13.4 \\
\hline BMT & 11.0 & 11.8 & 17.9 \\
\hline $\operatorname{ARR}(\%)$ & 5.9 & 5.4 & 4.6 \\
\hline RRR (\%) & 59 & 54 & 26 \\
\hline NNT & 17 & 19 & 22 \\
\hline
\end{tabular}

* ACAS = Asymptomatic Carotid Atherosclerosis Study; ACST = Asymptomatic Carotid Surgery Trial; ARR = absolute risk reduction; $\mathrm{BMT}$ = best medical therapy; NNT = number needed to treat; RRR = relative risk reduction.

fore and after (beginning in 2003) implementation of an intensive medical regimen. Medical therapy in the second time interval was aimed at reducing plaque progression and "burden" (measured as total plaque area and microemboli detected on transcranial Doppler [TCD] ultrasonography, respectively) rather than attaining target levels of blood pressure or plasma lipoproteins. During the most recent time interval considered, there was a significant increase in the use of statins, angiotensin-converting enzyme inhibitors, and antiplatelet agents. The new intensive medical management resulted in a significant reduction in the proportions of patients who experienced stroke or other cardiovascular events, the prevalence of microemboli on TCD ultrasonography, and the rate of plaque progression. Among patients enrolled before 2003, 17.6\% suffered cardiovascular events, compared with $5.2 \%$ of patients enrolled after 2003, when the new medical regimen was implemented. The prevalence of microemboli on TCD ultrasonography declined from $12.6 \%$ to $3.7 \%$, and the mean rate of plaque progression went from a mean of $69 \mathrm{~mm}^{2}$ per year to $23 \mathrm{~mm}^{2}$ per year. ${ }^{40}$

In 2009, a systematic review assessed temporal changes in reported stroke rates among patients with asymptomatic carotid artery stenosis treated with medical therapy alone and compared these rates to those observed in the major CEA trials. Eleven studies were included, with a total of 3724 patients who had received medical intervention alone and were followed over time. A statistically significant progressive reduction in the annual rates of stroke was evident. The risk of ipsilateral stroke decreased from $2.2 \%$ per year in 1995 to $1.0 \%$ per year in 2005 , and the risk of any territory stroke decreased from $3.5 \%$ per year to $2.2 \%$ per year during the same period. Specifically, it was found that by 2001, these rates fell below those of patients undergoing CEA in ACAS. ${ }^{1}$

The decreasing trend in stroke risk for patients on medical therapy is also evident looking at the results from ACAS and ACST. During the 15-year period between the publication of ACAS and the second report from ACST, the 5-year risk of ipsilateral stroke and any stroke fell significantly among patients assigned to the medical therapy arm. The 5-year risk of ipsilateral stroke fell by $67 \%{ }^{30}-$ from $11 \%$ in 1995, when ACAS was reported, to $3.6 \%$ in 2010, when the last data from ACST were published (Fig. 1). The same is evident when the 5-year risk of "any" stroke is considered; it was reduced by $59 \%$ - from $17.5 \%$ in 1995 to $7.2 \%$ in 2010 (Fig. 2).

\section{Current Status and Controversy}

Based on the growing evidence on the beneficial effects of current medical therapy in reducing the risk of stroke in patients with asymptomatic stenosis, many have suggested that the indications for invasive treatment must be reevaluated. Despite the benefit of CEA shown in ACAS and ACST, there is currently little agreement on the best therapeutic strategy for patients with asymptomatic carotid artery stenosis. This controversy is reflected in the contradictions evident among recent practice

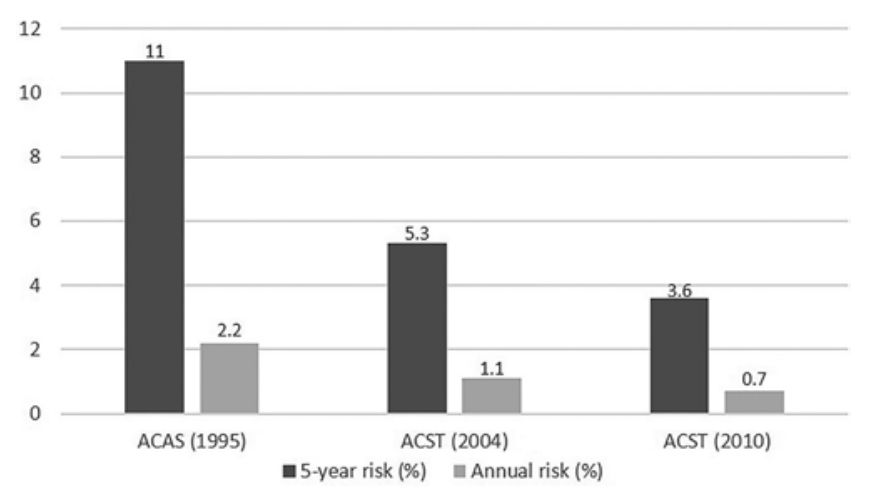

Fig. 1. Decreasing trends in the risk of ipsilateral stroke seen in patients with asymptomatic carotid artery stenosis randomized to medical therapy in ACAS and ACST. Data obtained from Naylor. ${ }^{30}$ 


\section{S. F. Morales-Valero and G. Lanzino}

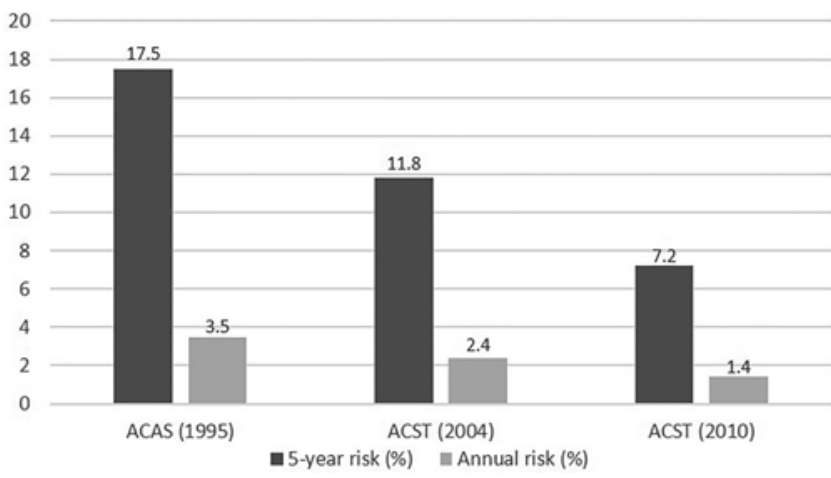

FIG. 2. Change in the 5-year and annual risk of any stroke over time among patients receiving medical therapy alone in ACAS and ACST. Data obtained from Naylor. ${ }^{30}$

guidelines on this topic published in 2011 by 6 different international groups. Although the different guidelines were based on the same supporting literature, there is a clear lack of consensus across different societies and countries on the management of asymptomatic carotid artery stenosis. $., 31,32,35$

The lack of agreement among the experts extends to the general medical journal readership as well. In 2008, the New England Journal of Medicine published the case of a 67-year-old male nonsmoker with hypertension and hyperlipidemia on adequate medical therapy, who was found to have a carotid artery bruit during routine examination. There was no previous history of ipsilateral or contralateral cerebrovascular ischemic symptoms. Diagnostic ultrasonography of his carotid arteries showed a $70 \%-80 \%$ stenosis on the side of the bruit, with an irregular plaque and elevated peak velocity, and 20\% stenosis on the contralateral side.$^{39}$ Readers were asked to choose the most appropriate treatment option for the patient based on experience, published literature, and current guidelines. This patient would be an ideal candidate for endarterectomy according to the guidelines of the American Heart Association. ${ }^{13}$ However, the opinion of the survey participants was different. Among the 4669 respondents from different countries, the majority $(49 \%)$ chose to treat the patient with medical therapy alone, about a third preferred CEA, and only $20 \%$ favored carotid artery stenting. ${ }^{21}$ Management was not different when only North American readers were considered, as $47 \%$ of them also voted for medical therapy alone. ${ }^{21}$

Proponents of invasive treatment state that in parallel with improvements in medical therapy, the perioperative risk of CEA and CAS has progressively decreased as well. ${ }^{38}$ In the CREST study, conducted between 2000 and 2008, the perioperative stroke risk in asymptomatic patients was $2.5 \%$ for CAS and $1.4 \%$ for CEA, the latter being significantly lower than that seen in ACAS and ACST. However, other considerations beside the reduced risk of ipsilateral stroke with best current medical therapy warrant a critical reevaluation of the role of invasive treatment of asymptomatic stenosis. One of them is the fact that the surgeons performing the interventions in ACAS and ACST were highly selected according to their expertise and complication rate record. ${ }^{31}$ This translates into difficulty generalizing the results to routine clinical practice, where periprocedural risk might be higher. In 2004, an analysis of 10 indications and outcomes of carotid endarterectomies performed in Medicare patients in 10 US states from 1995 to 1999 was published. The perioperative 30-day rate of stroke and death observed in this study was significantly higher than the corresponding rates reported in ACAS and ACST, reaching more than $5.0 \%$ in some states. ${ }^{23}$ The cost-effectiveness of revascularization is also a matter of debate, especially with the current trend to reduce health care costs. ${ }^{31,42}$ This problem is related to the high number needed to treat, calculated according to the ACAS results, indicating that 17 CEAs need to be performed to prevent one ipsilateral stroke, ${ }^{43}$ and this number could be greater if the recent advances in medical therapy are considered. It has been estimated that about $94 \%$ of the revascularization procedures are ultimately unnecessary and represent a considerable economic burden to the health system. ${ }^{31,32}$ It is because of this continued controversy that different trials comparing invasive treatment to best medical therapy are ongoing worldwide or in planning phase.

\section{Identification of Patients at High Risk for Stroke}

It is evident that the risk of stroke among patients with asymptomatic carotid artery stenosis treated with medical therapy alone has progressively declined during the last years. However, the risk is not 0\%; thus, recognition of subgroups of patients at higher risk of ipsilateral stroke would maximize the potential benefits of prophylactic revascularization..$^{24} \mathrm{~A}$ lot of research in recent years has focused on the identification of such "higher-risk" subgroups (Table 2).

\section{Clinical Features}

The Asymptomatic Carotid Stenosis and Risk of Stroke (ACSRS) study ${ }^{33}$ is the largest study done recently to identify subgroups of patients with carotid artery stenosis at higher risk of ipsilateral stroke. A total of 1121 patients were followed for a period of 48 months. A number of clinical and biochemical features were recorded at enrollment and a carotid artery ultrasound study was performed to determine the degree of stenosis and specific plaque characteristics. During follow-up, the occurrence of ipsilateral cerebral or retinal ischemic events was recorded. Clinical features found to predict an increased risk of ipsilateral ischemic events included increased systolic blood pressure, smoking history (more than 10 packyears), and history of contralateral TIAs or stroke..$^{33}$

\section{Plaque-Related Factors}

Severity of the degree of stenosis and its progression have been studied as possible predictors of ipsilateral stroke risk. Neither ACAS nor ACST showed any correlation between the degree of stenosis and the risk of ipsilateral stroke. ${ }^{16,43}$ However, the ACSRS investigators have observed an increased risk of stroke with increasing severity of the degree of stenosis. The risk of stroke increased from $0.6 \%$ per year in patients with mild stenosis $(50 \%-69 \%)$ to $1.9 \%$ per year in patients with severe 


\section{Management of asymptomatic carotid artery stenosis}

TABLE 2: Summary of some of the studies conducted to identify patients with asymptomatic carotid artery stenosis at high risk for stroke*

\begin{tabular}{|c|c|c|}
\hline Authors \& Year & High-Risk Marker Studied & Conclusions \\
\hline Nicolaides et al., 2010 & clinical features & $\begin{array}{l}\text { Elevated SBP (HR 1.07), smoking history }>10 \text { pack-yrs (HR 1.52) \& history of contralateral } \\
\text { TIAs or stroke (HR 3.03) increase the risk of ipsilateral stroke among patients w/ asymp- } \\
\text { tomatic carotid artery stenosis. }\end{array}$ \\
\hline Nicolaides et al., 2010 & degree of stenosis & $\begin{array}{l}\text { The annual risk of stroke increases } w / \text { the degree of stenosis }(0.8 \% / y r \text { for } 50-69 \%, 1.4 \% / \\
\text { yr for } 70-89 \%, \& 1.9 \% / y r \text { for }>90 \% \text { stenosis). }\end{array}$ \\
\hline Hirt, 2011 & stenosis progression rate & $\begin{array}{l}\text { An increase in the degree of stenosis by } 2 \text { or } 3 \text { prespecified categories over } 1 \mathrm{yr} \text { is related } \\
\text { to, respectively, a } 4 \text { or } 7 \text { times higher incidence of ipsilateral ischemic events in patients } \\
\text { w/ asymptomatic carotid artery stenosis. }\end{array}$ \\
\hline Nicolaides et al., 2010 & $\begin{array}{l}\text { plaque morphology on ultra- } \\
\text { sound }\end{array}$ & $\begin{array}{l}\text { The presence of Type } 1 \& \text { Type } 2 \text { plaques, large plaque areas, discrete white areas, \& low } \\
\text { gray-scale median increase the risk of stroke among patients w/ asymptomatic carotid } \\
\text { artery stenosis. }\end{array}$ \\
\hline Esposito-Bauer et al., 2013 & plaque morphology on MRI & $\begin{array}{l}\text { The presence of MRI-defined high-risk lesions characterized by intraplaque hemorrhage } \\
\& \text { a lipid-rich necrotic core increases the risk of ipsilateral ischemic events in patients w/ } \\
\text { asymptomatic carotid artery stenosis. }\end{array}$ \\
\hline Kakkos et al., 2009 & silent infarcts on CT & $\begin{array}{l}\text { Patients } w / \geq 60 \% \text { asymptomatic carotid stenosis \& ipsilateral infarcts of embolic origin on } \\
\text { CT have a higher annual risk of stroke than patients w/o these lesions ( } 3.6 \% \text { vs } 1.0 \%) \text {. }\end{array}$ \\
\hline Markus et al., 2010 & microemboli on TCD & $\begin{array}{l}\text { Among patients w/ asymptomatic carotid artery stenosis, the annual risk of ipsilateral } \\
\text { stroke is significantly higher if embolic signals are detected on } \operatorname{TCD}(3.6 \% \text { vs } 0.7 \%) \text {. }\end{array}$ \\
\hline Gupta et al., 2012 & cerebrovascular reserve & $\begin{array}{l}\text { Asymptomatic patients } w / \geq 70 \% \text { carotid artery stenosis \& impaired CVR are at increased } \\
\text { risk of cerebral ischemic events (OR } 3.86) \text {. }\end{array}$ \\
\hline Baker et al., 2000 & $\begin{array}{l}\text { contralateral carotid artery } \\
\text { occlusion }\end{array}$ & $\begin{array}{l}\text { The presence of contralateral carotid artery occlusion reduces the } 5 \text {-yr risk of stroke } \\
\text { among patients w/ asymptomatic carotid artery stenosis on medical therapy ( } 3.5 \% \text { vs } \\
11.7 \%) \text {. }\end{array}$ \\
\hline
\end{tabular}

* CVR = cerebrovascular reserve; SBP = systolic blood pressure.

stenosis $(\geq 90 \%) \cdot{ }^{33}$ An association between progression of stenosis and stroke risk was found in a post hoc subgroup analysis of patients enrolled in ACST. It was found that an increase in the degree of stenosis by 2 or 3 categories $(50 \%-69 \% ; 70 \%-89 \%$; 90\%-99\%; and $100 \%)$ over 1 year was related to an increase in the incidence of ipsilateral ischemic events by a factor of 4 or 7 , respectively. ${ }^{17}$

The ongoing advances in the understanding of the natural history of atherosclerosis have led to the identification of some features that may identify a more "unstable" plaque. Among these features are the presence of intraplaque hemorrhage, a large lipid-rich necrotic core, and a thin fibrous cap. ${ }^{29}$ With the use of imaging techniques such as ultrasonography and MRI, it is now possible to identify these high-risk plaques. Using ultrasound, atherosclerotic plaques can be characterized based on their echolucency and gray-scale values. Geroulakos and coworkers ${ }^{11}$ have developed a classification of carotid artery plaques, which was adopted by the ACSRS investigators $^{33}$ to predict the risk of ipsilateral ischemic events. In this study, patients with Type 1 and Type 2 plaques, which are echolucent and therefore lipid rich, had a significantly higher stroke risk $(3.0 \%$ per year) than patients with Type 3 and Type 4 (mainly echogenic) plaques $(0.8 \%$ and $0.4 \%$ per year, respectively). Other plaque features associated with stroke risk in the ACSRS study were low gray-scale median, presence of discrete white areas, and large plaque and juxtaluminal black areas. ${ }^{18}$

With continuous improvement in MRI, there has been increased interest in better definition of plaque composi- tion. A recent prospective study investigated the predictive value of plaque morphology as defined by MRI on the risk of stroke in patients with asymptomatic carotid artery stenosis. Eighty-three asymptomatic patients with 50\%-99\% carotid artery stenosis measured by Doppler ultrasonography were recruited during 5 years and underwent MR plaque imaging. Lesions were classified according to a

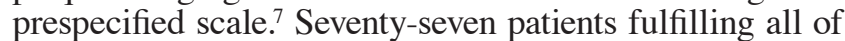
the study requirements were followed for a period of 41.1 months. A total of 9 ischemic cerebrovascular events were recorded (8 strokes and 1 TIA), all occurring in patients with "high-risk lesions" characterized by intraplaque hemorrhage and a lipid-rich necrotic core. ${ }^{10}$

\section{Silent Infarcts on CT}

The relationship between the clinically "silent" ipsilateral infarcts on CT scan and the risk of ipsilateral ischemic events in patients with asymptomatic carotid artery stenosis was prospectively studied in 821 patients constituting a subgroup of individuals enrolled in the ACSRS study who underwent CT examination of the head at baseline. ${ }^{19}$ A total of 146 patients were found to have ipsilateral infarcts of possible embolic origin. After a mean follow-up of 44.6 months, 102 ipsilateral ischemic events were documented (stroke in 47, TIA in 39, and amaurosis fugax in 16). Among patients with at least $60 \%$ stenosis, a significant difference was found between the annual stroke rate seen in patients with silent embolic infarcts on baseline CT compared with patients without these lesions (3.6\% vs $1.0 \%$, respectively). ${ }^{19}$ 


\section{S. F. Morales-Valero and G. Lanzino}

\section{Microemboli on TCD}

Transcranial Doppler ultrasonographic detection of microemboli, considered an index of "plaque" instability, has gained traction as one of the most powerful predictors of stroke risk in patients with asymptomatic stenosis., ${ }^{2,41}$ In the Asymptomatic Carotid Emboli Study (ACES), ${ }^{27}$ 482 patients with asymptomatic carotid artery stenosis of at least $70 \%$ were selected to undergo TCD at baseline and every 6 months thereafter to detect embolic signals. The main objective was to investigate if the presence of these signals was related to the risk of ipsilateral stroke and TIA. At baseline, 77 embolic signals were recorded, and 32 ipsilateral ischemic events occurred during follow-up (26 TIAs and 6 strokes). A clear association was found between embolic signals and risk of ipsilateral stroke (HR 5.57). The annual risk of ipsilateral stroke was $3.62 \%$ in patients with embolic signals and $0.7 \%$ in those without them.

\section{Cerebrovascular Reserve}

The impact of impairment of cerebral hemodynamics in patients with carotid artery stenosis (both symptomatic and asymptomatic) on stroke risk was investigated in a recent meta-analysis. Studies considered in this review were those that evaluated cerebrovascular reserve (either by TCD or nuclear medicine techniques) in patients with at least $70 \%$ carotid artery stenosis and recorded the occurrence of ipsilateral strokes or TIAs. This analysis of 13 studies with a total of 991 patients and a mean followup of 32.7 months found a strong association between impairment of cerebrovascular reserve and development of ischemic events (OR 3.86). This association remained significant regardless of symptomatic or asymptomatic status and outcome measure (stroke or TIA). ${ }^{14}$

\section{Contralateral Occlusion}

One would anticipate that patients with asymptomatic carotid artery stenosis contralateral to an occluded carotid artery are at higher risk of future stroke. Yet, a subgroup analysis of the ACAS study revealed an apparent paradox: patients with asymptomatic stenosis contralateral to an occlusion may actually have a lower risk of ipsilateral (to the asymptomatic stenosis) stroke. The predicted 5-year rate of stroke in patients with asymptomatic stenosis and contralateral occlusion enrolled in the medical arm was $3.5 \%$, which was significantly lower than the risk for patients without contralateral occlusion who were being treated with medical therapy (11.7\%). Considering that for the same group with contralateral occlusion, the 5 -year rate of stroke for patients undergoing endarterectomy was $5.5 \%$, it was concluded that surgical intervention in this group was not beneficial and could even be harmful. ${ }^{3}$

\section{Future Directions}

Despite the evidence from the large CEA trials, and given the ongoing controversy on the best management of asymptomatic carotid artery stenosis, randomization of patients to a "best" medical arm (best current medical treatment only) is considered justified by most clinicians. This consideration has led to the planning and launch of new clinical trials with the objective of assessing whether invasive treatment of asymptomatic carotid artery stenosis is still justified today and also better defining the role of CAS. The Stent-Protected Angioplasty in Asymptomatic Carotid Artery Stenosis versus Endarterectomy (SPACE-2) study is a 3-arm study that aims to recruit more than 3500 patients and randomly assign them to medical therapy alone or invasive treatment with CEA or CAS. ${ }^{37}$ Another ongoing trial is the Aggressive Medical Treatment Evaluation for Asymptomatic Carotid Artery Stenosis (AMTEC), which will also compare contemporary medical treatment to CEA. ${ }^{22}$ The CREST investigators in North America are also in the advanced planning phase of a similar study although the details have not been completely defined yet.

\section{Conclusions}

Carotid artery stenosis is a recognized risk factor for ipsilateral stroke. Although large randomized trials in the late 1980s and 1990s established a role for prophylactic CEA, growing evidence suggests that with modern advances in medical therapy, the risk of ipsilateral stroke in patients with asymptomatic carotid artery stenosis may be much lower than the risk observed in the large CEA trials, making CEA - or for that matter any invasive treatment-ineffective today. The controversy regarding the best treatment for asymptomatic carotid artery stenosis has stimulated many studies trying to identify specific subgroups of patients at higher risk for ipsilateral stroke who may benefit from prophylactic revascularization. Although several potential factors have been identified, the evidence is not strong enough to make definitive conclusions. Some ongoing large-scale trials comparing best current medical therapy versus invasive treatment (CEA and CAS) will shed more light on this controversial topic in the future. In the meanwhile, patients with asymptomatic carotid artery stenosis considered for invasive treatment should be carefully selected and counseled regarding the ongoing uncertainty about the best treatment strategy.

\section{Disclosure}

Dr. Lanzino reports a consultant relationship with eV3/Covidien and Codman.

Author contributions to the study and manuscript preparation include the following. Conception and design: both authors. Acquisition of data: both authors. Analysis and interpretation of data: both authors. Drafting the article: both authors. Critically revising the article: both authors. Reviewed submitted version of manuscript: both authors. Approved the final version of the manuscript on behalf of both authors: Lanzino.

\section{References}

1. Abbott AL: Medical (nonsurgical) intervention alone is now best for prevention of stroke associated with asymptomatic severe carotid stenosis: results of a systematic review and analysis. Stroke 40:e573-e583, 2009

2. Abbott AL, Chambers BR, Stork JL, Levi CR, Bladin CF, Don- 
nan GA: Embolic signals and prediction of ipsilateral stroke or transient ischemic attack in asymptomatic carotid stenosis: a multicenter prospective cohort study. Stroke 36:1128-1133, 2005

3. Baker WH, Howard VJ, Howard G, Toole JF: Effect of contralateral occlusion on long-term efficacy of endarterectomy in the asymptomatic carotid atherosclerosis study (ACAS). Stroke 31:2330-2334, 2000

4. Barnett HJ, Gunton RW, Eliasziw M, Fleming L, Sharpe B, Gates P, et al: Causes and severity of ischemic stroke in patients with internal carotid artery stenosis. JAMA 283:1429_ 1436, 2000

5. Brott TG, Halperin JL, Abbara S, Bacharach JM, Barr JD, Bush RL, et al: 2011 ASA/ACCF/AHA/AANN/AANS/ACR/ ASNR/CNS/SAIP/SCAI/SIR/SNIS/SVM/SVS guideline on the management of patients with extracranial carotid and vertebral artery disease: executive summary. Stroke 42:e420463, 2011

6. Brott TG, Hobson RW II, Howard G, Roubin GS, Clark WM, Brooks W, et al: Stenting versus endarterectomy for treatment of carotid-artery stenosis. N Engl J Med 363:11-23, 2010

7. Cai JM, Hatsukami TS, Ferguson MS, Small R, Polissar NL, Yuan C: Classification of human carotid atherosclerotic lesions with in vivo multicontrast magnetic resonance imaging. Circulation 106:1368-1373, 2002

8. de Weerd M, Greving JP, de Jong AW, Buskens E, Bots ML: Prevalence of asymptomatic carotid artery stenosis according to age and sex: systematic review and metaregression analysis. Stroke 40:1105-1113, 2009

9. de Weerd M, Greving JP, Hedblad B, Lorenz MW, Mathiesen EB, O'Leary DH, et al: Prevalence of asymptomatic carotid artery stenosis in the general population: an individual participant data meta-analysis. Stroke 41:1294-1297, 2010

10. Esposito-Bauer L, Saam T, Ghodrati I, Pelisek J, Heider P, Bauer M, et al: MRI plaque imaging detects carotid plaques with a high risk for future cerebrovascular events in asymptomatic patients. PLoS ONE 8:e67927, 2013

11. Geroulakos G, Ramaswami G, Nicolaides A, James K, Labropoulos N, Belcaro G, et al: Characterization of symptomatic and asymptomatic carotid plaques using high-resolution realtime ultrasonography. Br J Surg 80:1274-1277, 1993

12. Go AS, Mozaffarian D, Roger VL, Benjamin EJ, Berry JD, Borden WB, et al: Heart disease and stroke statistics-2013 update: a report from the American Heart Association. Circulation 127:e6-e245, 2013 (Erratum in Circulation 127:e841, 2013)

13. Goldstein LB, Bushnell CD, Adams RJ, Appel LJ, Braun LT, Chaturvedi $S$, et al: Guidelines for the primary prevention of stroke: a guideline for healthcare professionals from the American Heart Association/American Stroke Association. Stroke 42:517-584, 2011

14. Gupta A, Chazen JL, Hartman M, Delgado D, Anumula N, Shao H, et al: Cerebrovascular reserve and stroke risk in patients with carotid stenosis or occlusion: a systematic review and meta-analysis. Stroke 43:2884-2891, 2012

15. Halliday A, Harrison M, Hayter E, Kong X, Mansfield A, Marro J, et al: 10-year stroke prevention after successful carotid endarterectomy for asymptomatic stenosis (ACST-1): a multicentre randomised trial. Lancet 376:1074-1084, 2010

16. Halliday A, Mansfield A, Marro J, Peto C, Peto R, Potter J, et al: Prevention of disabling and fatal strokes by successful carotid endarterectomy in patients without recent neurological symptoms: randomised controlled trial. Lancet 363:14911502,2004

17. Hirt LS: Progression rate and ipsilateral neurological events in asymptomatic carotid stenosis. Stroke [epub ahead of print], 2011

18. Kakkos SK, Griffin MB, Nicolaides AN, Kyriacou E, Sabetai MM, Tegos T, et al: The size of juxtaluminal hypoechoic area in ultrasound images of asymptomatic carotid plaques predicts the occurrence of stroke. J Vasc Surg 57:609-618. e1, 2013

19. Kakkos SK, Sabetai M, Tegos T, Stevens J, Thomas D, Griffin M, et al: Silent embolic infarcts on computed tomography brain scans and risk of ipsilateral hemispheric events in patients with asymptomatic internal carotid artery stenosis. J Vasc Surg 49:902-909, 2009

20. King A, Shipley M, Markus H: The effect of medical treatments on stroke risk in asymptomatic carotid stenosis. Stroke 44:542-546, 2013

21. Klein A, Solomon CG, Hamel MB: Clinical decisions. Management of carotid stenosis-polling results. N Engl J Med 358:e23, 2008

22. Kolos I, Loukianov M, Dupik N, Boytsov S, Deev A: Optimal medical treatment versus carotid endarterectomy: the rationale and design of the Aggressive Medical Treatment Evaluation for Asymptomatic Carotid Artery Stenosis (AMTEC) study. Int J Stroke [epub ahead of print], 2013

23. Kresowik TF, Bratzler DW, Kresowik RA, Hendel ME, Grund SL, Brown KR, et al: Multistate improvement in process and outcomes of carotid endarterectomy. J Vasc Surg 39:372380,2004

24. Lanzino G, Couture D, Andreoli A, Guterman LR, Hopkins LN: Carotid endarterectomy: can we select surgical candidates at high risk for stroke and low risk for perioperative complications? Neurosurgery 49:913-924, 2001

25. Lanzino G, Rabinstein AA, Brown RD Jr: Treatment of carotid artery stenosis: medical therapy, surgery, or stenting? Mayo Clin Proc 84:362-387, 2009

26. Lanzino G, Tallarita T, Rabinstein AA: Internal carotid artery stenosis: natural history and management. Semin Neurol 30:518-527, 2010

27. Markus HS, King A, Shipley M, Topakian R, Cullinane M, Reihill S, et al: Asymptomatic embolisation for prediction of stroke in the Asymptomatic Carotid Emboli Study (ACES): a prospective observational study. Lancet Neurol 9:663-671, 2010

28. Marquardt L, Geraghty OC, Mehta Z, Rothwell PM: Low risk of ipsilateral stroke in patients with asymptomatic carotid stenosis on best medical treatment: a prospective, populationbased study. Stroke 41:e11-e17, 2010

29. Mughal MM, Khan MK, DeMarco JK, Majid A, Shamoun F, Abela GS: Symptomatic and asymptomatic carotid artery plaque. Expert Rev Cardiovasc Ther 9:1315-1330, 2011

30. Naylor AR: Asymptomatic carotid artery stenosis: state of the art management. J Cardiovasc Surg (Torino) 54 (1 Suppl 1): $1-7,2013$

31. Naylor AR: Time to rethink management strategies in asymptomatic carotid artery disease. Nat Rev Cardiol 9:116-124, 2012

32. Naylor AR: What is the current status of invasive treatment of extracranial carotid artery disease? Stroke 42:2080-2085, 2011

33. Nicolaides AN, Kakkos SK, Kyriacou E, Griffin M, Sabetai M, Thomas DJ, et al: Asymptomatic internal carotid artery stenosis and cerebrovascular risk stratification. J Vasc Surg 52:1486-1496.e5, 2010

34. Ovbiagele B, Nguyen-Huynh MN: Stroke epidemiology: advancing our understanding of disease mechanism and therapy. Neurotherapeutics 8:319-329, 2011

35. Paraskevas KI, Mikhailidis DP, Veith FJ: Comparison of the five 2011 guidelines for the treatment of carotid stenosis. J Vasc Surg 55:1504-1508, 2012

36. Perkins WJ, Lanzino G, Brott TG: Carotid stenting vs endarterectomy: new results in perspective. Mayo Clin Proc 85: 1101-1108, 2010

37. Reiff T, Stingele R, Eckstein HH, Fraedrich G, Jansen O, Mudra H, et al: Stent-protected angioplasty in asymptomatic carotid artery stenosis vs. endarterectomy: SPACE2 - a three- 


\section{S. F. Morales-Valero and G. Lanzino}

arm randomised-controlled clinical trial. Int J Stroke 4:294299, 2009

38. Schneider PA, Naylor AR: Transatlantic debate. Asymptomatic carotid artery stenosis-medical therapy alone versus medical therapy plus carotid endarterectomy or stenting. Eur J Vasc Endovasc Surg 40:274-281, 2010

39. Sila CA, Higashida RT, Clagett GP: Clinical decisions. Management of carotid stenosis. N Engl J Med 358:1617-1621, 2008

40. Spence JD, Coates V, Li H, Tamayo A, Muñoz C, Hackam DG, et al: Effects of intensive medical therapy on microemboli and cardiovascular risk in asymptomatic carotid stenosis. Arch Neurol 67:180-186, 2010

41. Spence JD, Tamayo A, Lownie SP, Ng WP, Ferguson GG: Absence of microemboli on transcranial Doppler identifies low-risk patients with asymptomatic carotid stenosis. Stroke 36:2373-2378, 2005
42. Thapar A, Garcia Mochon L, Epstein D, Shalhoub J, Davies AH: Modelling the cost-effectiveness of carotid endarterectomy for asymptomatic stenosis. Br J Surg 100:231-239, 2013

43. Walker MD, Marler JR, Goldstein M, Grady PA, Toole JF, Baker WH, et al: Endarterectomy for asymptomatic carotid artery stenosis. JAMA 273:1421-1428, 1995

Manuscript submitted September 4, 2013.

Accepted October 16, 2013.

Please include this information when citing this paper: DOI: 10.3171/2013.10.FOCUS13389.

Address correspondence to: Giuseppe Lanzino, M.D., Mayo Clinic, Department of Neurologic Surgery, 200 First St. NW, Rochester, MN 55905. email: Lanzino.Giuseppe@mayo.edu. 